\title{
New Case of Anti-Synthetase Syndrome Associated with Cirrhosis Post HVB
}

\author{
Hind Ômari, Ahmed Bellabah, Mohammed Tahiri, Fouad Haddad, Wafaa Hliwa, Wafaa Badre \\ Hepato-Gastroenterology Department UHC Ibn Rochd, Casablanca, Morocco \\ Email: dr.omari.hind@gmail.com
}

How to cite this paper: Ômari, H., Bellabah, A., Tahiri, M., Haddad, F., Hliwa, W. and Badre, W. (2019) New Case of Anti-Synthetase Syndrome Associated with Cirrhosis Post HVB. Open Access Library Journal, 6: e5753.

https://doi.org/10.4236/oalib.1105753

Received: September 2, 2019

Accepted: October 11, 2019

Published: October 14, 2019

Copyright $\odot 2019$ by author(s) and Open Access Library Inc.

This work is licensed under the Creative Commons Attribution International License (CC BY 4.0).

http://creativecommons.org/licenses/by/4.0/

\begin{abstract}
The anti-synthetase syndrome is represented by the association of inflammatory myopathy (polymyositis/dermatomyositis), interstitial pneumonitis, Raynaud's syndrome, inflammatory polyarthritis, and characteristic skin abnormalities. We found also a clinical aspects of Mechanic's hand with high level of anti-synthetases. We report the case of a 66-year-old patient with polyarthralgias of large and small inflammatory joints, myositis, Raynaud's phenomenon, and cutaneous involvement of the hands and feet, with fissure hyperkeratosis feet and an appearance of mechanic's hands. The patient had an inflammatory syndrome, elevated muscle enzymes, positivity of anti-Jo1 antibodies, PID at chest CT and the presence of inflammatory mononuclear cell infiltrates at muscle biopsy. The evolution under immunosuppressive treatment combining corticosteroids and methotrexate was marked by an oedemato-ascitic decompensation of a post-HVB cirrhosis unknown.
\end{abstract}

\section{Subject Areas}

Epidemiology, Gastroenterology \& Hepatology

\section{Keywords}

Cirrhosis, Hepatitis, HVB, Anti-Synthetase

\section{Introduction}

The anti-synthetase syndrome is an autoimmune disease clinically associating with interstitial lung disease (ILD), inflammatory myopathy (polymyositis/dermatomyositis), Raynaud's phenomenon, inflammatory polyarthritis and mechanic-type skin abnormality [1]. It is characterized by the presence of anti-aminoacyl transferase RNA synthetases, and an association with post-viral pathologies is possible. Our patient presents an anti-synthetase syndrome associated with post 
HVB cirrhosis in oedemato-ascitic decompensation.

\section{Observation}

This is a 66-year-old patient of Caucasian origin, having a history of pulmonary tuberculosis treated thirty years ago, being a chronic smoking drug weaned a year and a half ago. He presented a symptomatology evolving since one year made of polyarthralgias of large and small joints of inflammatory pace, a myositis with a myalgia associated with symmetrical proximal muscle weakness, a phenomenon of Raynaud as well as a cutaneous involvement of the hands and feet, with fissured hyperkeratosis of the feet (Figure 1) and an aspect of mechanic's hands.

The paraclinical assessment highlights:

We found an inflammatory syndrome with CRP $=28 \mathrm{mg} / \mathrm{l}$ and $\mathrm{CPK}=4521$ $\mathrm{U} / \mathrm{l}$.

The immunological report shows a positivity of antinuclear antibodies at 1/640 and in particular anti-nuclear antigen-resistant antibodies of anti-Jo-1 type at 90 $\mathrm{U} / \mathrm{ml}$. Anti-native DNA, rheumatoid factors and anti-CCP are normal.

\section{The radiological assessment showed:}

The absence of structural damage to X-rays of the various joints, a myogenic syndrome with EMG, an aspect of inflammatory myositis predominant on muscles proximal to muscle MRI and inflammatory infiltrates of perivascular mononuclear cells strongly suggestive of a polymyositis at the muscle biopsy. Diffuse interstitial syndrome with a micronodule appearance and thickening of the peri-bronchovascular and sub-pleural interstitium in CT and a mild-moderate restrictive syndrome with decreased $\mathrm{CO}_{2}$ transfer capacity indicating significant membrane involvement alveolar.
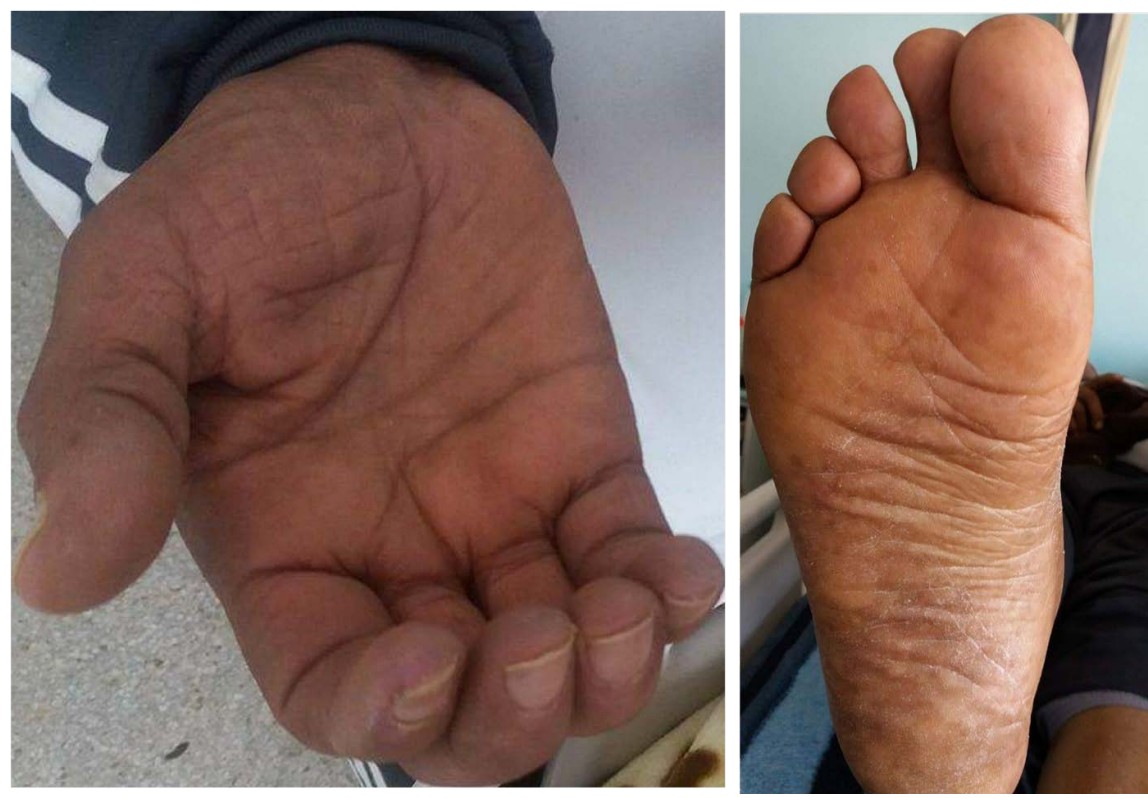

Figure 1. Shows the aspect of fissured hyperkeratosis of the hand and the feet. 


\section{ECG and transthoracic echocardiography are normal:}

The diagnosis of anti-synthetase syndrome is based on clinical presentation, the presence of CPK at $6321 \mathrm{U} / \mathrm{l}$, the positivity of anti-Jo1 antibodies, the presence of inflammatory mononuclear cell infiltrates on muscle biopsy and PID on the thoracic plane. The patient is treated with oral corticosteroids and methotrexate. The evolution was marked 3 months later by the appearance of an oedemato-ascitic syndrome made of soft edema of the lower limbs taking the bucket and a syndrome of peritoneal effusion of average abundance.

The biological assessment showed a disturbed hepatic assessment with ASAT at $83 \mathrm{U} / \mathrm{l}, \mathrm{ALAT}$ at $50 \mathrm{U} / \mathrm{l}, \mathrm{GGT}$ at $121 \mathrm{U} / \mathrm{l}$, a TP at $58 \%$, a Factor $\mathrm{V}$ at $53 \%$ and a hypo albuminemia at $19 \mathrm{~g} / \mathrm{l}$. A normal renal balance with a urea at $0.27 \mathrm{~g} / \mathrm{l}$, a creatinine at $10 \mathrm{~g} / \mathrm{l}$ and a proteinuria of $24 \mathrm{~h}$ at $0.06 \mathrm{~g} / 24 \mathrm{~h}$.

The radiological assessment showed an atrophic liver with irregular finely micronodular contours with ascites of great abundance Actitest: A2 Fibrotest: F4. The exploratory ascites puncture showed transudative ascites to $7 \mathrm{~g} / \mathrm{l}$ sterile with a gradient (albumin-blood albumin ascites) $>11$. Viral serologies have shown that $\mathrm{HVB}$ positive with a positive $\mathrm{HBsAg}$ at $2501.53 \mathrm{~S} / \mathrm{Co}$, and anti- $\mathrm{HBc}$ positive total at $11.49 \mathrm{~S} / \mathrm{Co}$ and a viral load at $8.74 \mathrm{Log}$. The serology of HVC was negative. FOGD showed grade I oesophageal varices.

The diagnosis of post-HVB cirrhosis in oedemato-ascitic decompensation associated with an antisynthetase syndrome was selected and the patient was put on diuretic and direct antiviral therapy. The evolution was marked by death following respiratory decompensation.

\section{Discussion}

The anti-synthetase syndrome is a systemic autoimmune disease characterized by autoantibodies directed against one of the many aminoacyl transfer RNA (tRNA) synthetases and which associates an inflammatory myopathy (polymyositis/dermatomyositis), an interstitial lung disease (ILD), Raynaud's phenomenon, inflammatory polyarthritis, and mechanic-type skin abnormality [1]. Among these criteria, our patient had clinical features consistent with PM/DM, Raynaud's phenomenon, and pigmented hyperkeratosis of the glabrous skin of the hands associated with fissures.

Anti-aminoacyl-transfer RNA synthetases, which characterize AS, include antihistidyl (OJ) detected in our case. The other antibodies that are part of the syndrome are: anti-threonyl (anti-PL-7), anti-alanyl (anti-PL-12), anti-glycyl (anti-EJ), anti-asparginyl (anti-KS), phenylalanyl (anti-ZO) and anti-tyrosyl-tRNA (anti-YRS) [2] [3]. Of these, anti-OJ-1 was the first antibody to be recognized and was detected in $20 \%$ to $30 \%$ of patients with PM or MS [4]. The pulmonary involvement is the severity of the syndrome, generally evolving to fibrosis, in the absence of treatment. It is responsible for an excess mortality of $40 \%$. It does not differ from that of other connectivity's [5] [6] and is initially manifested by a dry cough, then a dyspnea of effort. 
The different treatments used in case of SAA are corticoids and immunosupressors.

The efficacy of corticosteroids has been proven in articular, muscular and general manifestations, as well as in some pulmonary forms [7] [8]. Some observations of favorable evolution under cyclophosphamide [9] or tacrolimus [10] have been reported as well as the interest of cyclosporine A [11] [12]. Joffe et al. note a good response in methotrexate and especially azathioprine in the $2^{\text {nd }}$ line of treatment in 143 patients [13] with idiopathic inflammatory myopathies including 34 SAS. Intravenous immunoglobulins, validated in the second line in inflammatory myopathies [14], have not been specifically studied in pulmonary involvement of SAS. On the other hand, they have an efficacy on myositis with improvement of muscle testing and normalization of muscle enzymes [15] [16]. Our patient has been treated with oral corticosteroids and methotrexate. Hepatic involvement during SSA is rare and often caused by an autoimmune mechanism whose detailed pathogenesis is unknown [17].

Cases of patients with $\mathrm{HCV}$ infection who have developed inflammatory myopathy and interstitial lung disease have been reported [18], some of whom have developed cirrhosis and HCC [19]. The combination Polymyositis and $\mathrm{HCV}$ infection at or without HCC has been described with worsening clinical signs of myositis after hepatitis exacerbation, suggesting a close association between hepatitis B infection and myositis [20] [21].

Thus, immunosuppressants have been shown to pose a significant risk of stimulating the replication of many viruses, and increase the progression of fibrosis during viral hepatopathies $\mathrm{B}$ and $\mathrm{C}$. Therefore, in post-HVB cirrhosis, administration of these drugs should be associated with antiviral treatment [22]. For post-HVC cirrhosis, increased monitoring is recommended [23].

In our case, it was an SSA treated with immunosuppressants and triggering a œdemato-ascitic decompensation of an unknown post-HVB cirrhosis. In general, the poor prognosis of SAS is related to the frequency and severity of interstitial lung disease and its corticosteroids resistance, requiring the frequent use of immunosuppressants. Thus the association with other pathologies such as viral infections and cirrhosis makes the prognosis worse.

\section{Conclusion}

The syndrome of antisynthetases is an entity to know because of high level of morbidity and mortality. The diagnostic reaches the value for idiopathic inflammatory myopathies and the severity of the pulmonary involvement; treatment with corticosteroids and immunosuppressant should be initiated promptly, taken into consideration an association with other infectious or hepatic diseases.

\section{Conflicts of Interest}

The authors declare no conflicts of interest regarding the publication of this paper. 


\section{References}

[1] Connors, G.R., Christopher-Stine, L., Oddis, C.V. and Danoff, S.K. (2010) Interstitial Lung Disease Associated with the Idiopathic Inflammatory Myopathies: What Progress Has Been Made in the Past 35 Years? Chest, 138, 1464-1474. https://doi.org/10.1378/chest.10-0180

[2] Katzap, E., Barilla-LaBarca, M.L. and Marder, G. (2011) Antisynthetase Syndrome. Current Rheumatology Reports, 13, 175-181. https://doi.org/10.1007/s11926-011-0176-8

[3] Hirakata, M., Suwa, A., Nagai, S., Kron, M.A., Trieu, E.P., Mimori, T., et al. (1999) Anti-KS: Identification of Autoantibodies to Asparaginyl-Transfer RNA Synthetase Associated with Interstitial Lung Disease. The Journal of Immunology, 162, 2315-2320.

[4] Fischer, A., Swigris, J.J., du Bois, R.M., Lynch, D.A., Downey, G.P., Cosgrove, G.P., et al. (2009) Anti-Synthetase Syndrome in ANA and Anti-Jo-1 Negative Patients Presenting with Idiopathic Interstitial Pneumonia. Respiratory Medicine, 103, 1719-1724. https://doi.org/10.1016/j.rmed.2009.05.001

[5] Targoff, I.N., Trieu, E.P. and Miller, F.W. (1993) Reaction of Anti-OJ Autoantibodies with Components of the Multienzyme Complex of Aminoacyl-tRNA Synthetases in Addition to Isoleucyl-tRNA Synthetase. Journal of Clinical Investigation, 91, 2556-2564. https://doi.org/10.1172/JCI116493

[6] Chatte, G. and Boyer, J. (1992) Pneumopathie interstitielle fibrosante et dermatomyosite, Histologie pulmonaire et pronostic. Revue des Maladies Respiratoires, 9 , 634-635.

[7] Nine, H.M. and Nagai, S. (2000) Interstitial Lung Disease in Polymyositis and Dermatomyositis. Current Opinion in Rheumatology, 12, 501-508.

https://doi.org/10.1097/00002281-200011000-00005

[8] Costabel, U. and King, T.E. (2001) International Consensus Statement on Idiopathic Pulmonary Fibrosis. European Respiratory Journal, 17, 163-167.

https://doi.org/10.1183/09031936.01.17201630

[9] al-Janadi, M., Smith, C.D. and Karsh, J. (1989) Cyclophosphamide Treatment of Interstitial Pulmonary Fibrosis in Polymyositis/Dermatomyositis. The Journal of Rheumatology, 16, 1592-1596.

[10] Oddis, C.V., Sciurba, F.C., Elmagd, K.A. and Starzl, T.E. (1999) Tacrolimus in Refractory Polymyositis with Interstitial Lung Disease. The Lancet, 353, 1762-1763.

https://doi.org/10.1016/S0140-6736(99)01927-3

[11] Qushmaq, K.A., Chalmers, A. and Esdaile, J.M. (2000) Cyclosporin A in the Treatment of Refractory Adult Polymyositis/Dermatomyositis: Population Based Experience in 6 Patients and Literature Review. The Journal of Rheumatology, 27, 2855-2859.

[12] Tellus, M.M. and Buchanan, R.R. (1995) Effective Treatment of Anti Jo-1 Antibodypositive Polymyositis with Cyclosporine. British Journal of Rheumatology, 34, 1187-1188. https://doi.org/10.1093/rheumatology/34.12.1187

[13] Joffe, M.M., Love, L.A., Leff, R.L., Fraser, D.D., Targoff, I.N., Hicks, J.E., et al. (1993) Drug Therapy of the Idiopathic Inflammatory Myopathies: Predictors of Response to Prednisone, Azathioprine and Methotrexate and a Comparison of Their Efficacy. The American Journal of Medicine, 94, 379-387. https://doi.org/10.1016/0002-9343(93)90148-I

[14] Cherin, P., Pelletier, S., Teixeira, A., Laforet, P., Genereau, T., Simon, A., et al. (2002) Results and Long-Term Followup of Intravenous Immunoglobulin Infusions 
in Chronic, Refractory Polymyositis: An Open Study with Thirtyfive Adult Patients. Arthritis \& Rheumatology, 46, 467-474. https://doi.org/10.1002/art.10053

[15] Cherin, P., Herson, S., Wechsler, B., Piette, J.C., Bletry, O., Coutellier, A., et al. (1991) Efficacy of Intravenous Gammaglobulin Therapy in Chronic Refractory Polymyositis and Dermatomyositis: An Open Study with 20 Adult Patients. The American Journal of Medicine, 91, 162-168. https://doi.org/10.1016/0002-9343(91)90009-M

[16] Cherin, P. and Herson, S. (1999) Les immunoglobulines intraveineuses dans les polymyosites et les dermatomyosites. La Revue de Médecine Interne, 20, 436s-439s. https://doi.org/10.1016/S0248-8663(00)88675-0

[17] Lim, H.-W. and Silver, J. (2017) Not So Cryptogenic: An Unusual Case of Antisynthetase Syndrome and Cirrhosis. Hospital Medicine, Las Vegas, 1-4 May 2017, 4.

[18] Agha, B., Rasheed, M., Kenyon, L. and Jimenez, S.A. (2002) Hepatitis C Virus Infection, Inflammatory Myopathy, and Pulmonary Fibrosis: Are They Related? Journal of Clinical Rheumatology, 8, 44-49. https://doi.org/10.1097/00124743-200202000-00010

[19] Castañeda-Pomeda, M., Prieto-González, S. and Grau, J.M. (2011) Antisynthetase Syndrome and Malignancy: Our Experience. Journal of Clinical Rheumatology, 17, 458. https://doi.org/10.1097/RHU.0b013e31823b1878

[20] Thanapirom, K., Aniwan, S. and Treeprasertsuk, S. (2014) Polymyositis Associated with Hepatitis B Virus Cirrhosis and Advanced Hepatocellular Carcinoma. ACG Case Reports Journal, 1, 167-169. https://doi.org/10.14309/crj.2014.39

[21] Nojima, T., Hirakata, M., Sato, S., Fujii, T., Suwa, A., Mimori, T. and Ikeda, Y. (2000) A Case of Polymyositis Associated with Hepatitis B Infection. Clinical and Experimental Rheumatology, 18, 86-88.

[22] Droz, N., Gilardin, L., Cacoub, P., et al. (2013) Kinetic Profiles and Management of Hepatitis B Virus Reactivation in Patients with Immune-Mediated Inflammatory Diseases. Arthritis Care \& Research (Hoboken), 65, 1504-1514. https://doi.org/10.1002/acr.21990

[23] Ito, S., Nakazono, K., Murasawa, A., et al. (2001) Development of Fulminant Hepatitis B (Precore Variant Mutant Type) after the Discontinuation of Low-Dose Methotrexate Therapy in a Rheumatoid Arthritis Patient. Arthritis \& Rheumatology, 44, 339-342. https://doi.org/10.1002/1529-0131(200102)44:2<339::AID-ANR51>3.0.CO;2-Q 